\title{
Constitutive expression of c-fos and c-jun, overexpression of ets-2, and reduced expression of metastasis suppressor gene $\mathrm{nm} 23-\mathrm{H} 1$ in rheumatoid arthritis
}

Steven Dooley, Ivanna Herlitzka, Rainer Hanselmann, Ayhan Ermis, Wolfram Henn, Klaus Remberger, Thomas Hopf, Cornelius Welter

\begin{abstract}
Objectives-To identify genes that are involved in the development and progression of rheumatoid arthritis (RA). Methods-We used a multiple gene analysis system and a set of available genes participating in processes such as proliferation, differentiation, tumour progression, and metastasis, to identify their RA related expression. Synovial tissues from 22 patients with $R A$ were evaluated in comparison with those from six patients with osteoarthritis and two patients with non-inflamed joints as controls, using northern blot and reverse transcriptase polymerase chain reaction experiments. Results-Our data confirm the role of c-fos and c-jun as constitutive signal transmitters in solid RA tissues, thus demonstrating the potential of the approach. Activation of both genes persisted through multiple passages of the cells in tissue cultures derived from the synovial lining of RA tissues. There was an increased expression of ets-2 in $30 \%$ of $R A$ samples and an up to 30-fold decreased expression of the potential metastasis suppressor gene nm23-H1 in $90 \%$ of RA tissues, compared with control tissues.

Conclusions-The data presented show for the first time a significant decrease of nm23-H1 expression in RA, which is possibly involved in local invasiveness, and a strong activation of the ets -2 nuclear oncogene in about one third of RA tissues, which may also be part of a pathway leading to advanced disease stages. The constitutive expression of c-fos and c-jun in RA tissue most probably results from a continuing inflammatory stimulus. These findings with cell cultures suggest an intrinsic activation mechanism of these early response genes in $\mathrm{RA}$.
\end{abstract}

(Ann Rheum Dis 1996; 55: 298-304)

Rheumatoid arthritis (RA) is an inflammatory disorder characterised by infiltration of immunocompetent cells into the synovial tissue and synovial fluid of joints. Distinctive alterations in patterns of growth and cell-cell interactions characterise the rheumatoid synovium.
Most striking is the conversion of the lining cell layer from a predominantly single cell architecture into a multilayered proliferative cellular aggregation associated with changes in the cytomorphology of the synoviocyte. ${ }^{1}$ RA synovial tissue, which is rich in blood vessels, invades the periarticular cartilage and bone, destroying the joint. RA synovial fibroblasts are a major component of this invasive pannus, consisting of a vascular and fibrous granulation tissue arising from the joint recessus and extending onto the surface of the cartilage. A number of studies indicate that these fibroblasts are morphologically altered and highly activated, similar to phenotypic features that have been interpreted either as signs of reversible cellular transformation or as the result of strong, but reversible stimulation originating from the surrounding inflammatory microenvironment. ${ }^{2}{ }^{3}$ On the basis of these findings, a tumour-like expansion of the rheumatoid pannus tissue was suggested. ${ }^{4}$ In contrast, it has been proposed ${ }^{5-7}$ that the transitional fibroblastic zone frequently present in the cartilagepannus junction in rheumatoid joints is derived from the overlying cartilage. The origin of the destructive features of the rheumatoid synovium is not understood, and remains to be studied in detail. Using cytogenetic analysis, we have previously shown in primary cell cultures and higher passages of rheumatoid arthritis synovial tissue that trisomy 7 as a clonal change occurred in up to $20 \%$ of the cells analysed.$^{8}$ Interestingly, the proportion of cells having +7 increased with the duration of the in vitro culture.

We have now used a molecular approach to identify genetic parameters of the invasive and destructive behaviour of solid RA tissue. We investigated a set of genes involved in processes such as proliferation, differentiation, tumour progression, and metastasis, with respect to mRNA expression using a multigene dot and slot blot assay as described previously. ${ }^{10}$ Tissues obtained from patients diagnosed as having RA according to the American College of Rheumatology criteria ${ }^{11}$ were compared with disease controls (biopsy samples of patients with osteoarthritis (OA)). The data obtained by labelling reverse transcribed complementary DNA (cDNA) of a limited number of samples were enlarged in reverse transcriptase polymerase chain reaction (RT-PCR) and northern 
blot analysis to demonstrate significance. We also used the multigene analysis system to compare the pattern of expression of the above mentioned genes in cultures with low and high numbers of trisomy 7 cells.

\section{Materials and methods}

PATIENTS AND CELL CULTURING

Tissues were obtained from patients diagnosed as having RA according to the criteria of the American College of Rheumatology. ${ }^{11}$ As disease controls, tissues from six patients with OA were examined. Synovia (containing synovium infiltrating cells) were obtained either by synovectomy or during joint replacement surgery. Synovial fibroblast cell culturing was performed as described previously. ${ }^{8}$

RNA PURIFICATION AND NORTHERN BLOT ANALYSIS

Total RNA was isolated from rheumatoid or healthy tissues by the guanidinium thiocyanate-phenol-chloroform extraction method described by Chomczynski and Sacchi. ${ }^{12}$ Samples of $20 \mu \mathrm{g}$ total RNA were resolved by electrophoresis on $1 \%$ agaroseformaldehyde gels and transferred to GeneScreen nylon membranes according to the instructions of the manufacturer (NEN Du Pont, Boston, USA). After ultraviolet cross linking, the blots were hybridised at $65^{\circ} \mathrm{C}$ in $0.5 \mathrm{~mol} / 1$ sodium phosphate $(\mathrm{pH} 7 \cdot 2), 7 \%$ sodium dodecyl sulphate (SDS), and $1 \mathrm{mmol} / 1$ sodium EDTA for 16 hours as described by Church and Gilbert. ${ }^{13}$ After hybridisation, the membranes were washed once in $250 \mathrm{mmol} / \mathrm{l}$ sodium phosphate $(\mathrm{pH} 7 \cdot 2) / 1 \%$ SDS for 15 minutes and twice in $100 \mathrm{mmol} / \mathrm{l}$ sodium phosphate (pH 7.2)/1\% SDS for 15 minutes. Autoradiography was performed at $-70^{\circ} \mathrm{C}$ using intensifying screens. For multiple hybridisations, the bound probe was removed by incubating the filters twice for five minutes in $0.1 \times$ standard saline-citrate (SSC) $(3.0$ $\mathrm{mol} / \mathrm{l}$ sodium chloride $/ 0.3 \mathrm{~mol} / \mathrm{l}$ sodium citrate, $\mathrm{pH} 7 \cdot 0$ ) and $1 \%$ SDS at $95^{\circ} \mathrm{C}$. To ensure that removal was complete, the blots were exposed to radiographic film for two days.

\section{ANALYSIS OF GENE EXPRESSION PATTERNS}

RNA of five different RA tissues were used as substrate to prepare a first strand CDNA, which was labelled to high specific activity using random priming technology. In parallel, we tested direct labelling of the first strand cDNA with reverse transcriptase and $\alpha{ }^{32} \mathrm{P}$-desoxy ATP (dATP), which resulted in lower labelling efficiency. As controls, we hybridysed the same filters with total RNA probes from two healthy synovia samples and three samples of osteoarthritis tissues.

Total RNA (1-10 $\mu \mathrm{g})$ was added to a tube containing $0.5 \mu \mathrm{g}(100 \mathrm{nmol} / \mathrm{l})$ oligo desoxythymine in a total volume of $11 \mu \mathrm{l}$, heated to $70^{\circ} \mathrm{C}$ for 10 minutes, and then chilled on ice for five minutes. Six microlitres of magnesium chloride solution $(25 \mathrm{mmol} / \mathrm{l}), 3 \mu \mathrm{l}$ of
$10 \times$ PCR buffer II (Perkin Elmer), $2 \mu$ of each desoxynucleotide triphosphate (dNTP) $(10 \mathrm{mmol} / \mathrm{l}$ ), and $1 \mu \mathrm{l}$ of RNase inhibitor (20 $\mathrm{U} / \mu \mathrm{l})$ were added and the mixture placed on ice for two minutes before the addition of $1 \mu \mathrm{l}$ murine leukaemia virus reverse transcriptase $(50 \mathrm{U} / \mu \mathrm{l})$ and incubation for one to two hours at $42^{\circ} \mathrm{C}$. To verify the presence of first strand cDNA and to determine the length of the DNA fragments, $1 \mu l$ of $\alpha{ }^{32} \mathrm{P}-\mathrm{dATP}$ (Amersham, $3000 \mathrm{Ci} / \mathrm{mmol} / \mathrm{l}$ ) was added and the reverse transcriptase reaction checked by electrophoresis of $1 \mu l$ of the mixture through an agarose gel and exposure to radiographic film for one hour. Radioactive DNA probe was produced from the cDNA reaction by random priming in a total volume of $50 \mu$ l according to the manufacturers' procedures (Amersham, BRL, for example). The reaction was allowed to proceed at $37^{\circ} \mathrm{C}$ for two to four hours or overnight and then stopped by the addition of $1 \mu$ l EDTA $(0.5 \mathrm{~mol} / \mathrm{l})$. A Stratagene push column was used to separate probe from unincorporated radioactive nucleotides. The probe was used within one week. GeneScreen membrane (NEN/Dupont) and BioRad slot blot manifold or positively charged nylon membrane (Eppendorf), together with the Eppendorf-Event dot blot manifold, were used for binding of the various gene probes. Membranes were soaked with $0.4 \mathrm{~mol} / 1$ Tris, $\mathrm{pH}$ $7 \cdot 5$, for five minutes. The plasmid DNAs were denatured for 10 minutes at room temperature in $0.25 \mathrm{~mol} / 1$ sodium hydroxide $(\mathrm{NaOH}) / 0.5$ mol/l sodium chloride $(\mathrm{NaCl})$. The DNA probes were diluted in $0 \cdot 1 \times \mathrm{SSC} / 0 \cdot 125 \mathrm{~mol} / 1$ $\mathrm{NaOH}$ and bound to the membrane as one single slot of $1 \mu \mathrm{g}$ or in three different dilutions (250 ng, $25 \mathrm{ng}$, and $2.5 \mathrm{ng}$ ). The DNA samples were loaded into the manifold and left for 30 minutes before suction was applied. The membranes were removed from the manifold, neutralised by rinsing in $0.5 \mathrm{~mol} / \mathrm{l} \mathrm{NaCl} / 0.5$ $\mathrm{mol} / \mathrm{l}$ Tris, $\mathrm{pH} 7 \cdot 5$, dried in air, and then fixed by auto-ultraviolet cross linking using a Stratalinker (Stratagene). Hybridisation was performed as described for northern blot analysis.

SEMIQUANTITATIVE RT-PCR ANALYSIS Using total RNA preparations purified from different RA samples and several controls, we performed semiquantitative $R T-P C R$ reactions to investigate the expression of c-fos, c-jun, mad, max, c-myc, mxi1, ets-2, nm23-H1, nm23-H2, and $\beta$-actin. Five hundred nanograms of total RNA was reverse transcribed using the kit from Perkin Elmer as described in the manufacturer's procedure. Subsequent PCR was performed with $1 \mu l$ of the reverse transcriptase reaction using 15 pmol of each primer, $5 \mu \mathrm{l} 4 \mathrm{mmol} / \mathrm{dNTP}$ mixture (Stratagene, 1:25 dilution of stock), $10 \mu$ l Pharmacia Taq Polymerase buffer, and $2.5 \mathrm{U}(=0.5 \mu \mathrm{l})$ Taq Polymerase (Pharmacia) in a $100 \mu l$ reaction using a two step PCR as described in the Perkin Elmer RT-PCR kit manual. The number of cycles was decreased to 25 to ensure that exponential amplification was maintained. A $10 \mu l$ aliquot was analysed on $1-1.5 \%$ 
agarose gels, depending on the size of the resulting fragments.

DENSITOMETRIC ANALYSIS

RNA-PCR products and mRNA northern blot signals were quantitated densitometrically using a UMAX Powerlook scanner and a Power Macintosh computer with Adobe Photoshop 3.0, Magic Scan, and NIH-Image software by averaging three separate measurements of the left, middle, and right areas of each band. To correct for the varying amounts of RNA and PCR product loaded in each lane, all sample measurements were calculated as the ratio of the average areas between the specific transcript and the 28s ribosomal RNA (rRNA) or PCR product and $\beta$-actin. The value of $28 \mathrm{~s}$ rRNA obtained was defined as $100 \%$ and all other intensities were referred to it. Values thus calculated were indicated as $\%$ of the respective 28 s or $\beta$-actin signal intensity.

\section{PLASMIDS AND PROBES}

Protein coding gene probes used for northern blot analysis were labelled to high specific activity using random priming technology using hexanucleotide primers (c-fos, c-jun, ets-2, p53) and gene specific primers (nm23$\mathrm{H} 1)$. The probe used in control hybridisations was a synthetic 26 bp oligonucleotide selected from the human 28s rRNA sequence. ${ }^{14}$ Phosphorus-32 labelling in this case was achieved by T4 polynucleotide kinase (Biolabs). Probes dotted onto membranes were either created by PCR using gene specific primers, or used as recombinant plasmids. The primers were: junB (JunB (55); $1.5 \mathrm{~kb}$ human cDNA in Bluescript $\mathrm{KS}+$ ); junD (junD; $1.5 \mathrm{~kb}$ human cDNA in Bluescribe $\mathrm{M} 13+$ ); c-jun (5'-GCCTACAGATGAACTCTTTCTGGC3'upstream (up) and 5'-CTGAAACATCGCACTAGCCTTTGG-3'reverse (rev) primers from human cDNA sequence generating a 527 bp fragment); c-fos (5'-GGATAGCCTCTCTTACTACCAC-3'up and 5'-TCCTGTCATGGTCTTCACAACG-3'rev primers from human cDNA sequence generating a $280 \mathrm{bp}$ PCR fragment); fra1 (pSP fra $1 ; 1.5 \mathrm{~kb}$ human fra $1 \mathrm{cDNA}$ in pSP64); fosB (pTZ fosB; $1.7 \mathrm{~kb}$ human cDNA in pTZ18); L-myc (pLmyc 10; $1.8 \mathrm{~kb}$ human DNA in pJB327); $\mathbf{N}$-myc (pNb1; $1 \mathrm{~kb}$ human DNA in pBR322); c-myc (5'-CTCAACGTTAGCTTCACCAACAGG3'up and 5'-CTCCACATACAGTCCTGGATGATG-3'rev primers from human c-myc DNA sequence creating a 400 bp PCR fragment); max (5'-GGGCTCATCATAATGCACTGGAAC-3'up and 5'-TCTTCAGGCTCAGACTCTGAGCTG-3'rev primers from human max cDNA creating a 386 bp PCR fragment); mad (5'-GAAGAATAGACGGGCTCATCTTCG-3'up and 5'-TCTTAGAGACCAAGACACGCCTTG-3'rev primers creating a 474 bp PCR fragment); mxi1 (5'-AGCACTGCCAACAGATCTACACAC3'up and 5'-TGGCCCAGTGAATATTTTGCCCTG-3'rev primers, generating a $541 \mathrm{bp}$ PCR fragment); c-myb (pHM2.6; $2.6 \mathrm{~kb}$ human c-myb DNA in pKH47); erbB (pheB; $2.5 \mathrm{~kb}$ human erbB in pBR322); c-Ha-ras (pEJ6.6; 6.6 kb c-Ha-ras DNA in pBR322); c-Ki-ras (pSVE SW4A-9; $0.5 \mathrm{~kb}$ human c-Ki-ras DNA in M13 mp8); ets-2 (5'-ATGTCCAGGAAAGTGGCCAAGAAG-3'up and 5'-TGACATGGTTGTTTCCTTCCCACC3'rev primers creating a 336 bp PCR fragment); p53 (pR4-2; $1.7 \mathrm{~kb}$ human p53cDNA in pUC8); $\mathbf{R B}(\mathrm{p} 0.9 \mathrm{R} ; 0.9 \mathrm{~kb}$ human RBcDNA in pSP65); CD44 (5'-GACAGACACCTCAGTTTTTCTGGA-3'up and 5'-TTCCTTCGTGTGTGGGTAATGAGA-3'rev primers from human CD44cDNA creating a 400 bp PCR fragment); nm23-H1 (5'GGGCAGACCACATTGCTTTTC-3'up and 5'-GCTGGGAGGAAGCATTTTAATC-3'rev primers creating a 185 bp PCR fragment); nm23-H2 (5'-GAATAAGAGGTGGACACAACAGC-3'up and 5'-CCGGCTTCCAAAAGCTTTATTGGC-3'rev primers creating a 145 bp PCR fragment); pS2 (ppS2;0.3 kb human pS2cDNA in pT7T3); $\boldsymbol{\beta}$-actin (5'-GTCCTCTCCCAAGTCCACACA-3'up and 5'-CTGGTCTCAAGTCAGTGTACAGGTAA-3'rev primers from human cDNA creating a 300 bp PCR fragment); GAPDH (pBLUGAP; $1.4 \mathrm{~kb}$ rat GAPDHcDNA in pBluescript KS+); pBR322 (Boehringer Mannheim); pUC18 (Boehringer Mannheim).

\section{Results}

MULTIPLE GENE EXPRESSION ANALYSIS

Figure 1 shows a representative blot, and table 1 summarises the results. c-fos was active in all of five RA samples, whereas no or only weak signals were detected in controls. The ets-2 nuclear oncogene was positive in two of five RA tissues tested, and in one of three OA samples. $\mathrm{c}$-myb gave a very strong signal in two $\mathrm{RA}$ tissues and nm23 signals were decreased in all five RA samples compared with control hybridisations. In addition, occasional differences were found concerning the genes p53, fra $1, \mathrm{c}-\mathrm{myc}$, mad, fosB, max, c-Ki-ras, and the housekeeping gene GAPDH. A relatively constant amount of mRNA was found in al samples for $\mathrm{mxi}, \mathrm{RB}$, and $\beta$-actin. These preliminary data were used as basis for the investigation of a greater number of samples by RT-PCR and northern blot analysis.

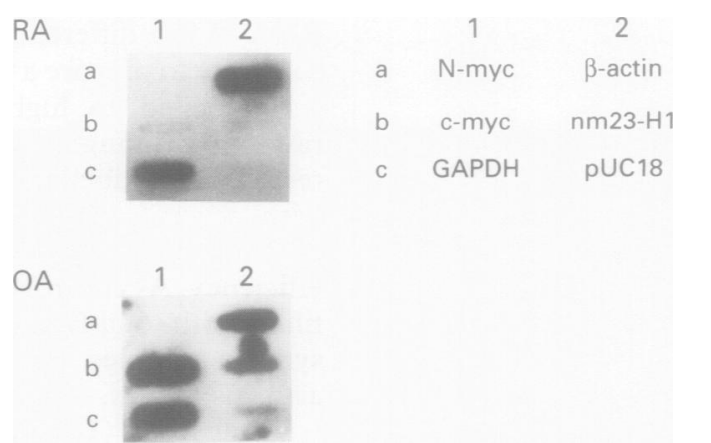

Figure 1 Representative slot blot autoradiography after filter hybridisation with rheumatoid arthritis specific $(R A)$ and osteoarthritis specific $(O A)$ whole $c D N A$ probes.

Positions of the target gene sequences are indicated. (Table 1 summarises the results of all the slot and dot blot experiments.) 
Table 1 Summary of the results of slot and dot blot experiments: number of samples among the five rheumatoid arthritis $(R A)$ tissues and five osteoarthritis $(O A)$ tissues expressing the different probes. Positions were evaluated as positive (different signal intensities not discriminated) or negative

\begin{tabular}{lll}
\hline & $\begin{array}{l}R A \\
(n=5)\end{array}$ & $\begin{array}{l}O A \\
(n=5)\end{array}$ \\
\hline c-fos & 5 & 1 \\
c-jun & 3 & 2 \\
c-myc & 1 & 3 \\
nm23-H1 & 0 & 3 \\
nm23-H2 & 2 & 2 \\
p53 & 1 & 0 \\
c-myb & 3 & 2 \\
ets-2 & 3 & 3 \\
mxil & 1 & 2 \\
L-myc & 0 & 0 \\
CD44 & 1 & 0 \\
N-myc & 0 & 0 \\
Ha-ras & 1 & 0 \\
junD & 1 & 1 \\
RB1 & 1 & 1 \\
fra1 & 3 & 3 \\
junB & 2 & 1 \\
pS2 & 1 & 0 \\
erbB-2 & 0 & 0 \\
N-ras & 0 & 2 \\
mad & 2 & 0 \\
c-Ki-ras & 1 & 1 \\
max & 4 & 5 \\
fosB & 2 & 5 \\
GAPDH & 5 & 0 \\
B-actin & 5 & \\
pUC18 & 0 & \\
pBR322 & 0 & \\
\hline
\end{tabular}

RT-PCR AND NORTHERN BLOT ANALYSIS

Table 2 summarises the results and figure 2 shows representative RT-PCR experiments. c-fos and c-jun analysis revealed strong PCR product signals in all the RA samples tested (fig 2B), while they were rarely obtained in controls (not shown). In contrast, c-myc was negative in most RA samples, but was expressed in OA samples (not shown). Max and mxi (not shown) were present at constitutive but very weak levels in all samples, and mad was expressed in single samples (fig 2A). The amount of $\mathrm{nm} 23-\mathrm{H} 1$ gene product (fig $2 \mathrm{C}$ ), but not that of $\mathrm{nm} 23-\mathrm{H} 2$, was significantly reduced in $\mathrm{RA}$ compared with OA control tissue. The data obtained by RT-PCR were partially verified in subsequent northern blot analysis (fig 3).

c-fos, c-jun, ets-2, nm23-H1, and p53 sequences were used as hybridisation probes. As has been reported previously by several other groups, a significant expression was found for c-fos, which was activated in $90 \%$ of RA samples (18 of 20); this underlines both the

Table 2 Summary of the results obtained in reverse transcriptase polymerase chain reaction analysis: target genes of the primer pairs and the rheumatoid arthritis and osteoarthritis samples used. The $\beta$-actin signal of each sample was taken as 1.0 and the densitometric data of each signal were correlated to it

\begin{tabular}{llllllllll}
\hline & Tissue & ets-2 & mad & $c$-fos & $c$-jun & $n m 23-H 1$ & nm23-H2 & mxi & $\beta$-actin \\
\hline KA & RA & 5.33 & 3.23 & 8.73 & 8.93 & 0.42 & 1.43 & 0.43 & 1.0 \\
AG & RA & 0.46 & 3.62 & 8.75 & 8.88 & 0.12 & 1.52 & 0.12 & 1.0 \\
LP & RA & 0.43 & - & 8.32 & 9.03 & 0.23 & 1.33 & 0.23 & 1.0 \\
LA & RA & 0.81 & 1.22 & 7.99 & 9.66 & 0.16 & 1.43 & 0.41 & 1.0 \\
AL & RA & 8.24 & 0.92 & 8.43 & 9.43 & 0.13 & 1.81 & 0.61 & 1.0 \\
MR & RA & 7.44 & 0.43 & 8.56 & 8.65 & 0.05 & 1.21 & 0.88 & 1.0 \\
SH & RA & 0.46 & 3.66 & 8.67 & 9.32 & - & 0.63 & 0.31 & 1.0 \\
KJ & RA & 0.33 & 0.33 & 8.56 & 8.42 & 0.20 & 0.34 & 0.12 & 1.0 \\
GI & RA & 4.66 & 0.35 & 9.13 & 8.13 & - & 0.98 & 0.13 & 1.0 \\
WI & RA & 5.39 & 1.33 & 8.33 & 9.43 & 0.16 & 0.32 & 0.33 & 1.0 \\
DE & RA & 0.62 & 4.12 & 7.54 & 9.34 & 0.13 & 1.43 & 0.41 & 1.0 \\
MB & RA & 0.58 & 1.23 & 8.65 & 9.55 & - & 1.36 & 0.94 & 1.0 \\
KM & RA & 0.26 & 0.23 & 8.67 & 8.63 & 0.06 & 1.88 & 0.32 & 1.0 \\
BJ & RA & 4.88 & 0.41 & 7.92 & 8.71 & 0.14 & 1.62 & 0.29 & 1.0 \\
SP & RA & 0.32 & 3.32 & 8.96 & 8.08 & 3.62 & 1.54 & 0.26 & 1.0 \\
WE & OA & 0.24 & 0.24 & 0.81 & 0.77 & 2.89 & 1.62 & 0.36 & 1.0 \\
FE3 & OA & 0.41 & 0.33 & - & 0.73 & 4.12 & 1.55 & 0.43 & 1.0 \\
SA & OA & 0.30 & - & 0.83 & 0.61 & 2.64 & 1.48 & 0.82 & 1.0 \\
HM & OA & 0.31 & 0.32 & - & 0.62 & 3.43 & 1.32 & 0.32 & 1.0 \\
\hline
\end{tabular}

importance of c-fos in rheumatoid arthritis signal transduction and the potential of our approach. Control tissues were negative for c-fos (two of five) or displayed a low level of transcripts (three of five). c-jun mRNA also was increased in about $50 \%$ of RA samples investigated (10 of 19), but some control tissues also were positive (two of five). We identified two different transcripts of 3.4 and $2.6 \mathrm{~kb}$ in RA and in control samples. It remains to be determined if this was the result of sequence homology of our human c-jun probe with other members of the jun family of transcription factors, or if there exist different splicing products. p53 transcripts were not detected in northern blot analysis (not shown), but ets- 2 transcripts were found in all samples (RA and controls) displaying at least a weak signal after one week of exposure time. In about one third of RA samples (six of 18), however, the expression of ets- 2 as demonstrated by densitometric analysis was significantly increased, by six to 20 -fold (figs $2 \mathrm{~A}$, 3B, tables 2, 3). Densitometric analysis also revealed the expression of $\mathrm{nm} 23-\mathrm{H} 1$ to be significantly decreased (two to 30-fold) (tables 2,3 ) in $90 \%$ of RA tissues ( 18 of 20 ) compared

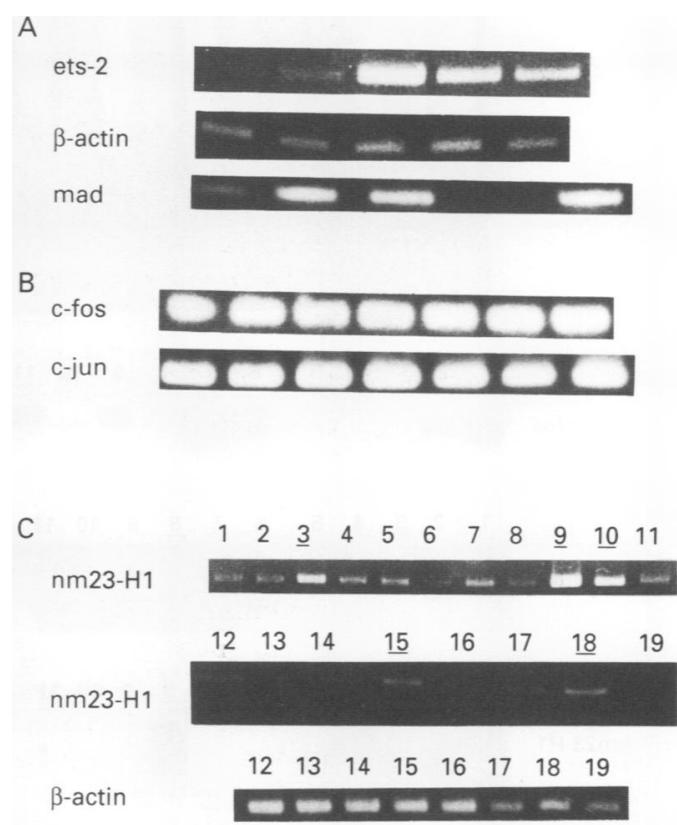

D

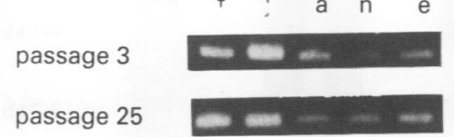

Figure 2 Reverse transcriptase polymerase chain reaction analysis using total $R N A$ from different rheumatoid arthritis $(R A)$ samples and some controls (underlined numbers) and primer pairs amplifying regions of the indicated genes. A: Five different $R A$ samples displaying enhanced expression of ets-2 and mad in three of five lanes; the signal intensities were referred to the $\beta$-actin product. B. Seven different $R A$ samples showing strong expression of both $c$-fos and c-jun genes. C: Nineteen different $R A$ and osteoarthritis (OA) (underlined) samples showing reduced amplification rate of $n m 23-H 1$ in $R A$. The $\beta$-actin control $P C R$ reaction is shown for samples 12-19. D: Comparison of the transcript level of several genes in early and late passage $R A$ cell cultures with different percentages of trisomy or polysomy 7 cells (passage 3: 5\% trisomy 7; passage 25: $54 \%$ trisomy or polysomy 7 ) $. f=c$-fos; $j=c-j u n ; a=\beta$-actin; $n=n m 23-H 1 ; e=e t s-2$. 
with OA samples. The RT-PCR experiments revealed no differences for $\mathrm{nm} 23-\mathrm{H} 2$ between RA samples and controls (not shown).

\section{CELL CULTURE EXPERIMENTS}

Comparison of primary fibroblastoid synovialis cell cultures with a low number of cells displaying trisomy 7 and higher passages with more than $50 \%$ trisomy or polysomy 7 cells did not yield different signal patterns with the gene probes tested. Transcripts for c-fos, c-jun, ets$2, \mathrm{~nm} 23-\mathrm{H} 1, \mathrm{~nm} 23-\mathrm{H} 2, \beta$-actin, and GAPDH were present, and no significant qualitative or quantitative differences could be detected in either dot blots or semiquantitative RT-PCR screening (fig 2D). This indicates that genes other than those analysed are affected by the increase of chromosome number 7 in RA cell cultures. It was very interesting that c-fos and c-jun expression, in common with findings for
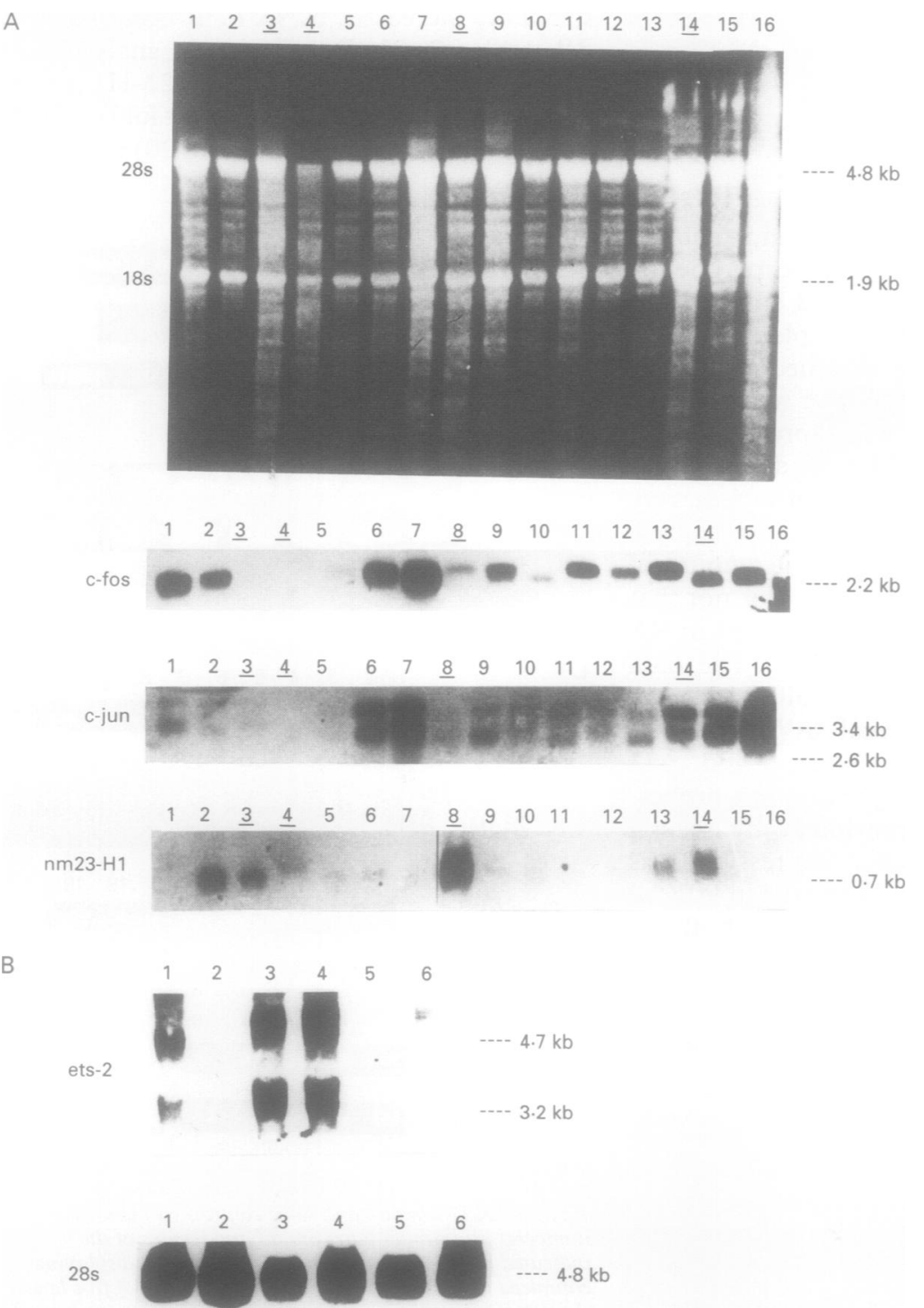

Figure 3 Northern blot analysis using total RNA of different rheumatoid arthritis (RA) and osteoarthritis $(O A)$ (underlined) samples. Hybridisation probes and the length of the corresponding RNA molecules are indicated. A: Significant activation of $c-f o s$ and $c-j u n$, and decreased expression of $n m 23-H 1$ in $R A$ tissue; 28 s ribosomal RNA band of the corresponding $R N A$ blots as reference. Variation of $R N A$ loading as a result of limited amounts of tissue from some samples. Differences were determined densitometrically (see table 3). With c-jun as probe, a $3 \cdot 4$ kb band not described previously was detected in $R A$ and control tissue. B: Four of six different $R A$ samples displaying strong expression of ets-2. Two signals, $4 \cdot 7$ and $3.2 \mathrm{~kb}$, also demonstrated in several other tissues. A 28 s specific oligonucleotide probe used as reference hybridisation.
Table 3 Summary of the results obtained in northern blot analysis. The 28 s ribosomal $R N A$ hybridisation signal value was taken as 1.0 in each sample and the densitometric measurements of the different probe signals were referred to it

\begin{tabular}{|c|c|c|c|c|c|}
\hline & Tissue & $c-f o s$ & $c-j u n$ & $e t s-2$ & $n m 23-H 1$ \\
\hline KA 12112 & RA & 0.88 & $0 \cdot 29$ & 0.92 & $0 \cdot 14$ \\
\hline AG 15102 & RA & 0.76 & 0.65 & $0 \cdot 18$ & 0.13 \\
\hline LP 12033 & RA & 0.85 & 0.54 & 0.15 & 0.13 \\
\hline LA 13074 & RA & 0.80 & 0.33 & $0 \cdot 10$ & 0.13 \\
\hline AL 19044 & $\mathrm{RA}$ & 0.68 & 0.59 & 0.81 & $0 \cdot 16$ \\
\hline MR 17064 & RA & 0.82 & 0.54 & 0.76 & $0 \cdot 14$ \\
\hline SH 14094 & $\mathrm{RA}$ & 0.71 & 0.32 & $0 \cdot 14$ & 0.12 \\
\hline KJ 04054 & $\mathrm{RA}$ & 0.73 & $0 \cdot 26$ & 0.12 & 0.13 \\
\hline ST 24114 & $\mathrm{RA}$ & 0.58 & $0 \cdot 70$ & 0.78 & 0.13 \\
\hline AA 24114 & RA & 0.81 & 0.65 & $0 \cdot 14$ & 0.14 \\
\hline DC 24114 & RA & $0 \cdot 64$ & 0.61 & 0.12 & 0.15 \\
\hline RH 03122 & RA & 0.85 & 0.33 & 0.13 & 0.32 \\
\hline GI 25084 & RA & 0.78 & 0.66 & 0.83 & 0.12 \\
\hline WI 21114 & RA & $0 \cdot 60$ & $0 \cdot 65$ & 0.77 & $0 \cdot 14$ \\
\hline DE 23033 & RA & 0.81 & 0.64 & $0 \cdot 12$ & 0.13 \\
\hline DM 27035 & RA & 0.72 & 0.56 & 0.12 & 0.14 \\
\hline MB 27035 & RA & 0.73 & 0.61 & 0.13 & 0.14 \\
\hline KM 03045 & RA & 0.69 & 0.72 & 0.12 & 0.13 \\
\hline BJ 31035 & RA & $0 \cdot 36$ & 0.33 & 0.79 & 0.12 \\
\hline SP 24035 & $\mathrm{RA}$ & 0.54 & 0.36 & 0.13 & $0 \cdot 30$ \\
\hline SE 02035 & $\mathrm{RA}$ & $0 \cdot 67$ & 0.63 & 0.11 & 0.34 \\
\hline TI 02035 & $\mathrm{RA}$ & 0.32 & 0.54 & 0.63 & $0 \cdot 26$ \\
\hline WE 12073 & OA & $0 \cdot 26$ & 0.34 & 0.13 & 0.39 \\
\hline FE 08055 & OA & 0.68 & $0 \cdot 29$ & 0.12 & 0.32 \\
\hline FE 30055 & OA & - & $0 \cdot 18$ & 0.12 & 0.48 \\
\hline SA 31055 & OA & $0 \cdot 22$ & $0 \cdot 23$ & 0.13 & 0.36 \\
\hline WI 16073 & OA & $0 \cdot 24$ & $0 \cdot 20$ & 0.12 & $0 \cdot 13$ \\
\hline HM 11014 & OA & - & $0 \cdot 18$ & 0.13 & 0.36 \\
\hline
\end{tabular}

solid probes, were also constitutively increased in cell cultures of fibroblastoid cells, which are not permanently under the influence of cells that are mediators of inflammation (fig $2 \mathrm{~B}$ ).

\section{Discussion}

In the rheumatoid synovium, abnormal gene programmes are activated that result in altered rates of proliferation and enable cells to invade the periarticular cartilage and bone, thus destroying the joint. A wide variety of mediators, factors, and possibly cell-cell interactions target the cell and activate distinct and separately regulated processes. It has been shown that fibroblasts derived from inflammatory synovitis displayed relative increases in the steady state concentrations of mRNA for the proinflammatory cytokine interleukin- 6 , the enzymes cathepsin $D$ and stromelysin (which are potentially capable of mediating tissue destruction and matrix remodelling), the cytoskeletal component vimentin, and major histocompatibility complex class II molecules, but diminished amounts of c-myc. ${ }^{9}$ We have used a recently described approach for further analysis of patterns of gene expression in rheumatoid arthritis. Because many genes are analysed simultaneously with relatively small amounts of RNA, the method is ideally suited for measurement of gene expression when tissue is scarce or the sample size is small. The preliminary results obtained with this technique were then investigated in more detail in RT-PCR and northern blot analysis.

First we found that c-fos was significantly activated in $90 \%$ of the solid RA tissues investigated. Similar data have been reported previously by several other groups and have already been discussed extensively. ${ }^{15}$ It is very interesting that a gene that physiologically undergoes transient activation as an early response gene is constitutively switched on in a disease model. One explanation is that this 
may represent a response to cytokines permanently released by immune and mesenchymal cells in the synovial lining and subsynovial layer. In contrast to this is the finding that c-fos is also constitutively activated in fibroblastoid cell cultures derived from the synovial lining of joints affected with rheumatoid arthritis. Its activity thus appears to be an intrinsic characteristic of these fibroblastoid cells, at least in cell culture, insofar as it was found to persist through multiple passages of the cells in the absence of an additional continuing inflammatory stimulus. In addition to c-fos, its partner c-jun is also induced in about $50 \%$ of RA samples, to a minor extent. In common with c-fos, c-jun is activated constitutively in cell culture. It remains to be clarified whether these data imply that there may be a long term response of these normally transiently activated genes, or that an exogenous stimulus is needed in RA tissues; a detailed analysis of the regulatory pathways involved in steady state activation of c-fos and c-jun, both of which have been significant markers for RA, will be very interesting. The immunohistochemical localisation of the gene products and a functional analysis at the protein level to clarify if the activities of both genes are mediated via heterodimerisation and AP1 motif binding are under investigation in our laboratory.

A further important finding was the detection of two different hybridisation signals in northern blot analysis with c-jun as probe $(2.6 \mathrm{~kb}$ regular, and a novel $3.4 \mathrm{~kb}$ band not described previously). We have begun to investigate if there are homologies between our PCR probe and another transcript (using Genbank computer search programs), if the two bands are specific for synovial samples (by investigating serum induced tumour cell lines with our c-jun probe), and if there are perhaps different transcription start sites in the gene (using reverse primer extension analysis of the transcripts).

ets-2 gene activity was found in RA samples and in controls (normal synovia and $O A$ samples), at least yielding a very weak mRNA hybridisation signal. Using RT-PCR analysis, which is a more sensitive system, it was possible to demonstrate this more impressively. In 33\% of RA tissues (six of 18), however, the transcription of ets-2 was increased six to 20 -fold (densitometric analysis). ets-2 transcripts were also detected in RA cell culture in early passages (small numbers of trisomy 7 cells) and in higher passages with more than $50 \%$ of trisomy or polysomy 7 cells. The members of the ets family are nuclear proteins ${ }^{16}{ }^{17}$ that can bind to specific DNA sequences located mainly in purine rich motifs. ${ }^{18} 19$ ets-2 mRNA can be detected in all tissues tested, but in highly variable amounts. Its expression has been associated with a proliferative role in many tissues, ${ }^{20}$ and therefore an enhanced activity in several RA samples may reflect disease progression. In this context, it is of importance that several known genes involved in the degradation of the extracellular matrix, such as those encoding stromelysin 1, collagenase, and urokinase plasminogen activator, ${ }^{21}$ contain ets binding sites in their regulatory flanking sequences. In this way, ets- 2 may play a part in coordinating events that lead to the degradation of cartilage - an important process in invasive growth. Why an increased expression of ets- 2 was found only in about $30 \%$ of RA samples remains unclear. It may be hypothesised that other, ets- 2 independent, pathways exist that have the same effect as ets- 2 overexpression. The same problem is encountered with the analysis of oncogene expression in human cancer, in which again only a proportion of tumours of the same histological type display changes in activity characteristic of distinct oncogenes. Nevertheless, it would be of value to investigate the specific role of the ets- 2 gene product in rheumatoid synovialis cells.

In view of the fact that a basic feature of joint damage in RA is the progressive erosion and destruction of articular cartilage and adjacent connective tissues, our data on nm23 are very important. The $\mathrm{nm} 23$ gene was originally identified on the basis of its reduced mRNA and protein levels in highly metastatic melanoma cell lines. ${ }^{22}$ Two nm 23 gene isoforms, $\mathrm{nm} 23-\mathrm{H} 1$ and $-\mathrm{H} 2$, both encode $17 \mathrm{kDa}$ proteins. ${ }^{23}$ Generally, the published data indicate that a reduced concentration of $\mathrm{nm} 23$, or its structural alteration, result in a loss of the suppressor function. In agreement with this hypothesis, we detected a reduced $\mathrm{nm} 23-\mathrm{H} 1$ transcript level in $90 \%$ of the RA samples investigated, compared with $\mathrm{OA}$ or normal synovialis tissue. This finding provides evidence that $\mathrm{nm} 23$ may be involved in the invasive behaviour of rheumatoid synovialis cells, as in the process of metastatic spread of specific tumours. As is the case for the metastatic process in human and animal tumours, at present we do not know the underlying function of the $\mathrm{nm} 23$ proteins in RA tissues. Some of the identified gene activities we describe have not yet been investigated in detail (c-myb, for example) and will be the subject of future study; others did not change significantly in comparison with controls, or occurred rarely in the sample pool as a whole, and were therefore disregarded.

Because use of this assay was limited to the gene probes available in our laboratory, we are now aiming to establish a differential mRNA extraction cloning strategy that allows us to identify new gene markers of RA in comparison with OA samples.

We are grateful to $\mathrm{H}$ Janz for excellent technical and photolaboratory assistance, and to B MÅller for preparing the tissue samples. This work was supported by a grant from the Deutsche Forschungsgemeinschaft DFG/HO 1275/4-1.

1 Burmester G R, Dimitriu-Bona A, Waters S J, et al. Identification of three major synovial lining cell populations by monoclonal antibodies directed to Ia antigens and antigens associated with monocytes/macrophages and fibroblasts. Scand $\mathcal{F}$ Immunol 1983; 17: 69-82.

2 Schuhmacher H R, Kitridon R C. Synovitis of recent onset: a clinico-pathologic study during the first month of disease. Arthritis Rheum 1972; 15: 465-75.

3 Harris E D. Recent insights into the pathogenesis of the proliferative lesion in rheumatoid arthritis. Arthritis proliferative lesion in
Rheum 1976; 19: 68-78.

4 Fassbender H G. Inflammatory reactions in arthritis. In: Davies M E, Dingle J T, eds. Immunopharmacology of joints and connective tissue. London, San Diego, New York, 
Boston, Sydney, Tokyo, Toronto: Academic Press, Harcourt Brace and Company, Publishers, 1994; 166-98.

5 Allard S A, Maini R N, Muirden K D. Cells and matrix expressing cartilage components in fibroblastic tissue in $125-9$.

6 Muirden K D, Allard S A, Rogers K, et al. Immuno-electron microscopy of chondrocyte derived cells in the rheumatoid cartilage pannus junction. Rheumatol Int 1988; 5: 231-4.

7 Allard S A, Muirden K D, Camplejohn K L, et al. Chondrocyte derived cells and matrix at the rheumatoid pannus-cartilage junction identified with monoclonal antibodies. Rheumatol Int 1987; 7: 153-9.

8 Ermis A, Hopf T, Hanselmann R, et al. Clonal chromosome aberrations in cell cultures of synovial tissue from patients with rheumatoid arthritis. Genes Chromosom Cancer 1993; 6: $232-4$.

9 Ritchlin C, Dwyer E, Bucala R, et al. Sustained and distinctive patterns of gene activation in synovial fibroblasts and whole synovial tissue obtained from inflammatory synovitis. Scand F Immunol 1994; 40: 292-8.

10 Chalifour L E, Fahmy R, Holder E L, et al. A method for analysis of gene expression patterns. Anal Biochem 1994; 216: 299-304

11 Arnett F C, Edworthy S M, Bloch D A, et al. The American Rheumatism Association 1987 revised criteria for the classification of rheumatoid arthritis. Arthritis Rheum 1988; 31: 315-24.

12 Chomczynski P, Sacchi N. Single-step method of RNA isolation by acid guanidinium thiocyanate-phenolisolation by acid guanidinium thiocyanate-phenol-

13 Church G M, Gilbert W. Genomic sequencing. Proc Nat Acad Sci USA 1984; 81: 1991-5.
14 Barbu V, Dautry F. Northern blot normalization with a $28 \mathrm{~S}$ rRNA oligonucleotide probe. Nucleic Acids Res 1989; 17: 7115.

15 Ritchlin C T, Winchester R J. Potential mechanisms for coordinate gene activation in the rheumatoid synoviocyte: implications and hypotheses. Springer Semin Immunopathol 1989; 11: 219-34.

16 Fujiwara S, Fisher R J, Bhat N K, et al. A short-lived nuclear phosphoprotein encoded by the human ets-2 protooncogene is stabilized by activation of protein kinase C. Mol Cell Biol 1988; 8: 4700-6.

17 Koizumi S, Fisher R J, Fujiwara S, et al. Isoforms of the human ets-1 protein: generation by alternative splicing and differential phosphorylation. Oncogene 1990; 5: 675-681.

18 Bosselut R, Duvall J F, Gegonne A, et al. The product of the c-ets-1 proto-oncogene and the related Ets2 protein the $C$-ets-1 proto-ongeat of human T cell leukemia virus HTLV-1. EMBO ₹ 1990; 9: 3137-44.

19 Klemsz M J, McKercher S R, Celada A, et al. The macrophage and B cell-specific transcription factor PU.1 is related to the ets oncogene [see comments]. Cell 1990; 61: 113-24.

20 Bhat N K, Fisher R J, Fujiwara S, et al. Temporal and tissuespecific expression of mouse ets genes. Proc Natl Acad Sci USA 1987; 84: 3161-5

21 Macleod K, Leprince D, Stehelin D. The ets gene family. Trends Biochem Sci 1992; 17: 251-6.

22 Steeg P S, Cohn K H, Leone A. Tumor metastasis and nm23: current concepts. Cancer Cells 1991; 3: 257-62.

23 Stahl J A, Leone A, Rosengard A M, et al. Identification of a second human nm23 gene, nm23-H2. Cancer Res 1991; 51: $445-9$ 